\title{
Learning Package by Means of the Inductive Teaching with Group Process
}

\author{
Benchaporn Sawangsri \\ Faculty of Science and Technology, Rajamangala University of Technology Suvarnabhumi, Thailand
}

Copyright $(2016$ by authors, all rights reserved. Authors agree that this article remains permanently open access under the terms of the Creative Commons Attribution License 4.0 International License

\begin{abstract}
This research focuses on the inductive teaching with group process and students' behavior as working in a group. There were four instruments under this study. The descriptive statistics were employed. The findings revealed that, firstly, the effectiveness of LPIDTGP is higher than the fixed criteria. Secondly, the students' learning achievement is higher than the fixed criteria. Thirdly, the students' behavior as working in a group, as the overall, is good. Lastly, the students' learning satisfaction towards LPIDTGP is greatly satisfied.
\end{abstract}

Keywords Derivative, Group Process, Inductive Teaching, Learning Package

\section{Introduction}

In the education circumstance, the good education management should consider the learner's characteristics. They are different in terms of knowledge, personality, and creative thinking. The learners should be active students. The learners should also be encouraged to express their knowledge and feeling while in the class.

Mathematics is considered as one of the high effective tool. It is used to describe various fields of knowledge and it is also well-known acknowledged. According to [1], the problems for mathematics learning were that the topics taught in the classes were quite difficult. Thus, this made the learners dislike mathematics, including that there were no effective materials to stimulate the learners' interest.

Rajamangala University of Technology Suvarnabhumi, Suphanburi, Thailand is the educational institute for science and technology. One of compulsory courses offered is Calculus I. Its content includes important functions, limit and continuity, derivatives, and integrals derivative. From observation for several years, many undergraduates at Faculty of Engineering and Architecture and Faculty of Industrial Education faced a difficult time when they study Calculus I. This is because they may lack of background knowledge of this course. Their problematic topic is
Derivative, which is the fundamental for higher courses or related courses. So, learners should understand this topic thoroughly, and they can apply knowledge for other courses.

[2] said that learning package is a self-learning tool for students. The learning package includes instruction card, activity card, content card, exercise card, worksheets and keys, and tests with keys.

[3] said that instructional package refers to various learning materials combined together. Its objective is to enable learners learn effectively. It is also called multimedia, learning package, instructional package, or instructional kits.

[4] described learning package as the multimedia created systematically. It is complete and relates to the course content, which creates the learning effectively.

[5] said that learning package is a format of communication between teachers and learners. It comprises of the directions for learners to help them achieve the target as the teachers planned.

Inductive teaching is one approach considered more effective. The students will be encouraged to learn new knowledge as working in a group [6]. This supports the strategies for teaching students in the $21^{\text {st }}$ century that the collaborative skill is the great approach that promotes students' learning [7]

[8] described inductive teaching as a comparison method. The learners should observe such as pictures and examples. Then, they were required to make conclusion.

[9] described the inductive teaching as the teaching without explaining the concepts. The learners observed the examples and then group them into the suitable classifications. After that, the learners summarized or explained this concept.[10] explained the inductive teaching as teaching from examples to the rules. The learners observed, studied, experimented, compared, and considered the elements for the conclusion.

Group process is the study about a group of people. The outcomes from this study help to change the person's attitude and behavior. This can lead to the effective working group and increase good relationship. [11] cited in [12], group process was the result from member's relationship. The group structure was from various characters. This caused the 
member's interaction in terms of feeling and thoughts. The members adjusted themselves and tried to work together. They used their own ability which pushed forward to meet success. So, this idea could be used for teaching. Students learned how to work with other people. According to Education Committee (1997), students are the child center. All students can participate in the activities as a group. Group is the good and important resource for creating learners' understanding and interest. Group can also adjust students to get along with the other members in the group. Students created their own concepts. Teachers are the facilitators who support students' learning. Teachers are also the motivators who motivate students to find out the knowledge.

From the statements above, it can be referred that teaching mathematics should motivate learners to think and discover new knowledge or the principles by inductive teaching method, integrated with group process. Moreover, mathematics teaching material such as learning package should be used for supporting learners' understanding. In this study, "derivative", one of essential topic, is brought to create the learning package.

\section{The Objectives of the Study}

1) To develop the Learning Package by means of the Inductive Teaching with Group Process (LPIDTGP) for undergraduates at Rajamangala University of Technology Suvarnabhumi.

2) To investigate the students' learning achievement towards LPIDTGP by based on the fixed criteria as $65 \%$

3) To examine the students' behavior as working in a group towards LPIDTGP.

4) To study the students' learning satisfaction towards LPIDTGP.

\section{The Scope of the Study}

The content is used in this study was on the topic of "Derivative." The sampling was the undergraduates enrolling in Calculus 1 in 2015. Purposive sampling was used to obtain the sampling. The independent variable was LPIDTGP. The dependent variable consisted of the students' learning achievement, the students' behavior as working in a group, the students' learning satisfaction towards LPIDTGP.

\section{Literature and Theoretical Framework}

Under this study, five theoretical frameworks were described as follows:

\section{A. The theories concerning learning packages}

The learning package is one of the innovations playing a vital role to enhance the learners' learning achievement. This is because the learning package is the combination of multi-media. It is a useful tool for teachers to transfer their knowledge and experience into concrete format. Teachers have opportunities to join learning activities concerning the individual's difference. Learners can practice learning individually or as a group. Student can implement the working process with rational thinking with the appropriated systematic planning [13] Learning package normally consists of related course objectives, content, learning experiences. It also supports the learners for the continual learning. Thus, after using the learning package, the learning achievement is higher. [14]

\section{B. The theories about the inductive teaching}

[8]Inductive instruction makes use of student "noticing". Instead of explaining a given concept and following the explanation with examples, the teacher presents students with many examples showing how the concept is used, according to [9]-[10] stated that inductive teaching was the teaching procedure from details to the main topics, or teaching from observing, testing, or comparing from the information provided and then concluding the principles or rules from what they learnt. This teaching method enables learners to learn by heart and last long memory. The learners have logical thinking. They understand how to solve the problems correctly. Hence, the inductive teaching approach is suitable for the learners who can construct their own idea. In other words, inductive teaching method is also effective for developing perceptual and observational skills. Students not only learn content but they also learn how to process data and how to use it to meet at appropriate conclusions.

[15] Inductive teaching method can solve a problem from the particular to the general, helps students to discover important rules or truths for themselves through careful observation of among specific examples. If students understand the rule or generalization, they should be able to apply it to other problems or exercises. The advantages are that it makes the students think logically and scientifically. What is learned is retained longer and is better understood. The students are trained in problem solving and are able to solve similar problems later.

\section{The theories about the group process teaching}

Group processes are especially significant in twenty-first century schools. Group projects and cooperative teamwork are the foundations of effective teaching, creative curriculum, and positive classroom climate. Group processes are also significant in modern global communities, where citizens must work together for a safe and secure world. Thus, along with teaching academic curriculum, teachers are expected to help students develop the attitudes, skills, and procedures of democratic community.

Group process learning is occurred when learners collaborate as a group. Group influenced learners' learning. 
According to Education Committee, the methods for group learning process can be explained as follows: First, learners are the child center. Everyone can participate in any activities. Next, group is one of the important resources for learning. Learners can gain new knowledge and learn how to adapt themselves with the others. Teachers play a role as the facilitator or motivator in order to stimulate learners to find out the answers or discover new knowledge. Last, learning process is realized as the important tool for discovering new things. Teachers should pay attention on the process to acquire the answers or concepts.

Group process can be categorized into two main steps: First, the objectives must be set, both general objectives and behavioral objectives. Second, learning experiences should be conducted. The latter steps consist of leading to the topic, teaching, analyzing the data, summarizing and applying new knowledge, and evaluating data.

Group learning process can be divided into various purposes. For example, if the teachers have a specific purposes, groups can be divided into gender. Group can be classified in terms of individual's satisfaction. They will join the group with their preferences. However, this should not be often conducted because students may lack the opportunities to work with other people from another group. Specific group is one of learning process. Students with high ability may work with someone's lower ability. They will finally help each other to carry out their mission.

\section{Teaching and learning mathematics}

Teaching mathematics should be corresponded with the curriculum's objectives. Learners should be practical in order to be able to solve the problems. Many scholars explained the teaching methods of mathematics as follows.

[16] said that teaching mathematics should be considered many aspects such as learners' readiness, feeling, intellectual, and background knowledge. Teachers should revise the previous knowledge in order to help support the new knowledge before being introduced to the class. So, learners would be able to understand and observe the relationship of something they learnt well. In addition, creating mathematics should fit learners' age, need, interest, and ability. Teachers should pay attention to the individual's difference and teach from simple to complex topics. Teachers should manage the time when teaching, not too short or long time. Working as a group could help support learners to learn better. Good attitude should be taught to learners in order to satisfy learners when studying mathematics.

[8] explained how to teach mathematics as the following. Mathematics should be taught from simple to complicate topics. The abstract knowledge should be transferred to be concrete knowledge. The teaching materials should be used for the concrete knowledge and support learners' learning. In addition, teaching methods should be varied. Games, songs, or pictures can be used in the class. It also interested the learners to be more interesting when studying mathematics. Learners should be taught to observe and summarize the concepts by themselves.

[17] explained that learners should be able to observe and discover the concepts by themselves. They should be more creative and can apply the concepts without memorizing or intimating. Questions could be used for stimulating learners to think and discover principles. This could enable learners to have a skill for solving problems. The knowledge should be also linked up with the concrete knowledge.

\section{E. Previous studies}

[11] studied the learning achievement with group process in the class. The finding showed that students' learning achievement was over the fixed criteria. In addition, students in the group had a strong interaction to each other. Students also paid more attention while studying mathematics in the class.

[18] investigated the teaching methods by means of group process towards life skills and learning's achievement. It showed that students' life skills and learning achievements were higher.

[19] examined the potential and learning achievement by using group learning process. The finding revealed that students had much more understanding about the content and had a high skill when working as a group. They could work efficiently and systematically. Students had more attention and enthusiasm when working as a group. This was in line with [20]-[22] in that group process was the people's collaboration with the same aim. Everyone in the group had a significant role to push the group forward.

\section{Research Design and Methodology}

\section{A. The instruments employed in this study were as follows:}

a) The Learning Package by means of the Inductive Teaching with Group Process (LPIDTGP)

b) The Evaluation Form for the Learning Package by means of the Inductive Teaching with Group Process

c) The Learning Achievement Test

d) The Group Work's Behavior Assessment Form

e) The Satisfaction Evaluation Form towards the Learning Package by means of the Inductive Teaching with Group Process

\section{B. The instruments' development and verification}

The inductive teaching approach was employed for the creation of learning packages. The benefit of learning package was that learners could study by themselves with their own interests. Integrated learning packages with inductive teaching, it enable the learners to have the high effectiveness. Moreover, new idea was generated from this process. The group process was employed in order to create the members' cooperation in the group. The learners helped 
each other to complete their tasks. As a result, the instruments utilized in this study were developed and verified as following:

a) The development of the LPIDTGP. The development procedure for the LPIDTGP was studied. Then the draft of the LPIDTGP was outlined. Next, it was verified by the experts.

b) The development of the Learning Achievement Test. First, the test was constructed, covering the contents and objectives. Next, it was verified by the experts. A pilot study was conducted before using with the target group.

c) The development of the Group work's Behavior Assessment Form. The theoretical frameworks about the group work's behavior were studied. This assessment form consisted of five parts. It was verified by the experts and adjusted before using with the target group.

d) The development of the Students' Satisfaction Evaluation Form. This evaluation form was 5-rating scale. It was verified by the expert.

\section{Data Collection}

1. Prepared the Learning Package by means of the Inductive Teaching with Group Process to test with the target group (LPIDGP).

2. Conducted the experiment, the steps as follows:

2.1 Explained instructions to the students how to use LPIDTGP, the learning management, duration, and evaluation approach. This was to ensure that the mistakes would be lessened.

2.2 Divided students into a group of 4 . It consisted of a student with high competency, 1 student was with medium competency, and 2 students with low competency. This regarded the students' willingness, too.

2.3 Proceeded the activities by using LPIDTG. After that, tested the students' learning achievement individually.

3. Evaluated the students' behavior as working in a group and their learning satisfaction towards LPIDTGP.

3.1 Administered the evaluation form to the students. The evaluation was divided into 3 parts: student's evaluation; peer's evaluation; and teacher's evaluation. The students firstly evaluated themselves, following by peers and teachers.

\section{Data Analysis and the Descriptive Statistics under this Present Study}

The data analysis was as follows: First, the teaching approach, the learning activities, and the evaluation approach were analyzed by IOC. Second, the effectiveness of the Learning Package by means of the Inductive Teaching with Group Process was analyzed by the fixed criteria as $E_{1} / E_{2}$. Third, the learning achievement score was compared by average, S.D., and t-Test. Last, the group work's behavior and the students' learning satisfaction towards LPIDTGP were analyzed by average and S.D.

\section{Results}

Based on the research purposes, the results of data analysis were as follows:

1. The experts' opinions towards the learning package were that all topics were at the highest level. It can be interpreted as very good. Regarding the average and S.D., it showed that each learning package was nearly suitable, as shown in Table 1.

2. The effectiveness of the learning package was 83.44/83.99, which was higher than the fixed criteria. It implied that, as hypothesized, this LPIDTGP was effective.

3. The students' learning achievement was 90.91. It indicated that this LPIDTGP was effective.

4. The students' behavior as working in a group, as the overall, was 2.61. It could be interpreted as good. Considering in details, it appeared that students were good at task achievement $(\bar{X}=2.72)$

5. The students' learning satisfaction towards LPIDTGP was at the highest level $(\bar{X}=4.56, S . D .=0.24)$. Considering in details, students were happy and satisfied at $\operatorname{LPIDTGP}(\bar{X}=4.84, S \cdot D=0.12)$.

Table 1. The average and S.D. of the experts towards the learning packages

\begin{tabular}{|c|c|c|c|}
\hline & Average & S.D. & Interpretation \\
\hline algebraic function & $\mathbf{4 . 3 1}$ & $\mathbf{1 3 .}$ & very good \\
\hline logarithmic function & $\mathbf{4 . 3 1}$ & $\mathbf{1 2 .}$ & very good \\
\hline exponential function & $\mathbf{4 . 2 9}$ & $\mathbf{1 1 .}$ & very good \\
\hline trigonometric function & $\mathbf{4 . 3 3}$ & $\mathbf{0 9 .}$ & very good \\
\hline $\begin{array}{c}\text { inverse trigonometric } \\
\text { function }\end{array}$ & 4.34 & .11 & very good \\
\hline
\end{tabular}

\section{Discussion and Conclusion}

\section{A. The effectiveness of the LPIDTGP}

The finding indicated that the effectiveness of LPIDTGP was $83.44 / 83.89$. This is because the researcher planned to develop the learning package well. The learning package was researched from various trustworthy papers and verified by the experts. This finding supports [13], [14] studies that the development of the learning package should be corresponded the contents, activities, and objectives. The learning package is combined and verified. Thus, it could also change the learner's behavior.

\section{B. The students' learning achievement}

The finding showed that LPIDTGP could enable students to gain higher learning achievement score at $90.91 \%$. This is 
because students can learn the new knowledge. They can also work in a group very well. For example, they helped each other to make sheets and worksheets, including giving a presentation well. The students also have freedom to learn and practice the LPIDTGP. This finding is also consistent with [17] that the learning package is the multi-media combined as the package. The learning package should be consisted of simple contents. The activity instructions should not be too complicated. The content does not need to be in sequence. In addition, the knowledge from the sheet is related to the worksheet and can be checked through the answers. This proves [14] that the learning package can increase the students' learning achievement because the learning package is supported by the learning continually. Moreover, the students can practice the learning package at any times. This is also consistent with [8] in which that teaching mathematics should be from simple to complicated topics. It also supports [17] that teaching mathematics should focus on observation. This finding also proves[11] and [18]-[21] that the inductive teaching creates students to be more active and take participation in this approach better.

\section{The students' behavior as working in a group towards LPIDTGP}

The findings appeared that the students' behavior, as the overall, is 2.61. It can be interpreted as "good." Considering in details, it shows that the learning achievement is the most concerned, following by the participation and responsibility, and the students' role. This is because learning with the group process emphasizes the students' collaboration. All members in the group tried to achieve the task. This supports the Educational Committee (1997) that the group process has a great influence on students' learning in the group and makes students work together. It is consistent with [21]-[22] studies that learning with the group process can increase the students' learning achievement and make students behave well when working as a group.

\section{The students' learning satisfaction towards LPIDTGP}

The results showed that the students' learning satisfaction towards LPIDTGP is the highest. Considering in details, it appears that the students are happy and satisfied with LPIDTGP. This is because this learning approach helps students to have freedom to do the activities and do not feel stress. In addition, the contents and the activities correspond to the students' needs and learning experiences. This supports [21], [23] studies that group process learning makes students greatly happy and satisfied at it.

\section{REFERENCES}

[1] Karnkirati, W. 2001. Mathematics Management. Mathematics and Computer Division Faculty of Science and Technology, Rajabhat University Phet-buri.

[2] Pipitkul, Y,Tantibanjong, A. 1988. Innovation of Teaching Mathematics. Faculty of Education, Chulalongkorn University.

[3] Srisa-ard, B. 1988. Development of Instruction. Bankok : Chomromdek.

[4] Nonthamolee, W. 2009. A construction of Instructional package Art Education "creative sculpture" for Phathomsuksa III student. An Independent study for Master Education in Educational Technology, Faculty of Education, Khon Kaen University.

[5] Kapfer,P. and M. Kapfer. 1972. Instruction to learning package. Learning package in American Education. Englewood Cliffs, N.J.: Educational Technology Publication.

[6] Moonkam, S. 2002. 21 Methods: Learning Management to Develop Thinking Process. Bangkok: Doungkamol -Samai.

[7] Taechakup, P. et al. 2013. Genius Strategy to Enhance 21st Century Skills. Presentations Seminar Educa 2014.

[8] Pipitkul, Y. 1987. Learning and Teaching Mathematics. Bangkok:Bopit -Printing.

[9] Pilantananon, N. 1999. Learning Concept. Chawprayasystem Printing.

[10] Fakkhaew, S. 2001. Principle of Teaching to Professional Teacher. Bangkok: Aeampan.

[11] Prapong, W. 2012. The learning process in the classroom together to achieve achievement of commercial law for Diploma student year III Chiang Rai High School. Report of study in Instruction. Chiang Rai.

[12] Roopngam,Y.2002. Participant in Commissioner Bureau of the Budget to reform the bureaucracy. Liberal of Arts, National Institute of Development Admintration.

[13] Khanhawet, B. 1999. Innovation in Education. Bangkok : Chareanwit printing.

[14] Phromwong, C. 1978. Teaching System. Bangkok: Chulalongkorn University Press.

[15] Boonchuwong, S. 2001. Model of Teaching. Faculty of Education Suan -Dusit Rajabhat University.

[16] Yooboonchom, B. 1986. Teaching and Learning Mathematics Behaviors in Primary School. Bangkok: O-Dian Printing.

[17] Cheasuwantawee, C. 1999. Teaching Mathematics. Curriculum and Instruction, Srinakarinwirot University.

[18] Chaichana , U. 2007.The effect of teaching with group process in life skills of the students of secondary grade one of Hatyai Wittayalai Somboon Kulakunya School. Master of Education, Taksin University.

[19] Ngamprapasom,P. 2012. To Increase the Potential and Learning Achievement by Using Group Learning Process. Lampang Rajabhat University Journal.

[20] Lewin, K. 1951. Field. Theory and Leaning Ind. Cartwright 
Field Theory in Social Science: Selected Theoretical Papers. New York: Harper and Row.

[21] James B. S. 1998. The Effects of Diversity on Small Work Group Processes and Performance. Human Relation. Vol51, No10.
[22] Kaemanee, T. 2002. Model of Teaching: New Dimension. Bangkok: Chulalongkorn University Press.

[23] Khuanhawet, B. 2000. Education Innovation. Bangkok: SP Printing. 